\title{
Minimum ST Segment Elevation
}

National Cancer Institute

\section{Source}

National Cancer Institute. Minimum ST Segment Elevation. NCI Thesaurus. Code C62159.

The minimum elevation of the ST segment, obtained from a set of measurements of the elevation of the ST segment. 